\title{
EDITORIAL
}

\section{Vision 2020: on the home stretch}

\section{Visão 2020: na reta final}

\author{
Jayter Silva Paula ${ }^{1}$, João Marcello Furtado ${ }^{1}$, João Paulo Souza², Van Charles Lansingh ${ }^{3}$
}

\begin{abstract}
Current efforts for strengthening ocular care worldwide are evident but still not sufficient to provide equitable eye care in many places around the world, particularly in under-resourced countries. Despite the decrease on the global prevalence of visual impairment in the last two decades ${ }^{(1)}$, the main cause of blindness (cataract) as well as the main cause of moderate or severe visual impairment (uncorrected refractive errors) could be averted or treated ${ }^{(2)}$. The VISION 2020: The Right to Sight initiative, created by the World Health Organization (WHO) and the International Agency for Prevention of Blindness (IAPB), is the main global program to eliminate avoidable blindness since its launch, in 1999.

Through the analysis of key indicators, VISION 2020 has been monitoring continuously eye health interventions. Its targets were updated in the $66^{\text {th }}$ World Health Assembly, based on lessons learnt from 2009 to 2013 , when the most recent action plan was released: the WHO Global Action Plan 2014-2019 - Towards Universal Eye Health ${ }^{(3,4)}$. Also, specific regional strategies have been proposed, such as the VISION 2020 Latin America (V2020LA) Strategic Plan for 2013-2016 and the Pan American Health Organization Action Plan 2014-2019. These regional plans are important because they provide local members from global and regional organizations a common strategy towards implementing the $\mathrm{WHO}$ objectives and optimize their collaboration regionally ${ }^{(5)}$.

Initial analyses had projected 76 million blind people in 2020 throughout the world ${ }^{(6)}$, but this number would be hardly reached because recent compiling results have shown a number of 32.4 million blind individuals ${ }^{(1)}$. Since the relative and absolute older population has grown worldwide, the fact that the number of blind people remained almost stable during the last decade ${ }^{(1)}$ is an indicator of success of the measures.

Considering the advances observed but the large underserved population, a review of actions and an evaluation of cost-effectiveness must be made in countries supported or not by any branch of VISION 2020 program. Fortunately, actions targeting control of sight-threatening diseases have been constantly revised by health care providers, government, and global institutions such as the WHO and IAPB. As an example, in the 1980's, infectious diseases such as trachoma and onchocerciasis played a major role in blindness prevention, and in recent years the importance of chronic eye conditions such as glaucoma, diabetic retinopathy and age-related macular degeneration has increased ${ }^{(2)}$. These chronic eye conditions present more difficult public health interventions and the success in controlling them depends especially on adequate national policies. In countries where avoidable blindness had been increasingly controlled and is no longer considered an issue, new concerns have been focused on visual impairment strategies (e.g. Uruguay)(5,7).

Vision 2020, in its first 12 years proved to be effective in delivering equitable eye health services in remote locations, with economic rates of return of $20 \%{ }^{(3)}$. However, considering those changes in the social and health profiles, VISION 2020 must "scale up" with focus on closer alignment and integration with local primary health system and advocacy with major government health programs. The WHO Global Action Plan 2014-2019 was developed around 3 main objectives: (1) generate evidence on the regional or local magnitude and causes of visual impairment and eye care services in order to enhance advocacy; (2) implementation of national health policies and programs aligned with WHO's framework for improving local health systems; (3) stimulation of effective multisectoral partnerships to strengthen eye health ${ }^{(3,4)}$.

A very important lesson learnt is that VISION 2020 initiative cannot depend on a sole contact in each country to effectively implement its program goals and objectives. In Latin America, VISION 2020 has been especially effective in establishing national committees with representation and participation of private and public stakeholders. Collaboration between both sectors was encouraged and helped the development of many national plans in the region ${ }^{(5)}$. However, in recent years, the concept and importance of committees have unfortunately diminished in this region, where some countries could not establish committees for some time, or they have been dormant. The approval of those new WHO plans and the global indicators data collection proposal, which are now required by member states, has resulted in a re-awakening of the national committee concept in Latin America. For example, committees have been reactivated in Peru, Mexico and Uruguay.
\end{abstract}

Submitted for publication: October 13, 2014

Accepted for publication: October 14, 2014

${ }^{1}$ Department of Ophthalmology, Otorhinolaryngology and Head and Neck Surgery, Ribeirão Preto Medical School, Universidade de São Paulo, São Paulo, SP, Brazil.

Department of Social Medicine, Ribeirão Preto Medical School, Universidade de São Paulo, São Paulo, SP, Brazil.

${ }^{3}$ International Agency for the Prevention of Blindness, Queretaro, Mexico and Instituto Mexicano de Oftalmologia, Queretaro, Mexico.
Funding: No specific financial support was available for this study

Disclosure of potential conflicts of interest: None of the authors have any potential conflicts of interest to disclose.

Corresponding author: Jayter Silva Paula. Departamento de Oftalmologia. Faculdade de Medicina de Ribeirão Preto - Universidade de São Paulo. Av. Bandeirantes, 3900/12 andar - Ribeirão Preto SP - 14049-900 - Brazil - E-mail: jspaula@fmrp.usp.br 
Other important accomplishment of VISION 2020 Latin America is a push for evidence-based medicine to guide national policies and programs on eye care ${ }^{(5)}$, such as some Rapid Assessment of Avoidable Blindness (RAAB) studies performed in the last three years ${ }^{(8)}$. New ideas aimed at the current VISION 2020 Latin America challenges should be carried through in most regional countries, especially those based on the development and continuous maintenance of technical local teams or subcommittees acting as manager of eye care activities as well as the achievement of funding resources to keep members engaged and productive.

While elimination of avoidable blindness by 2020 may not be possible as originally planned, the VISION 2020 initiative has identified bottlenecks and a roadmap to strengthening local health systems and improve ophthalmological services around the world. Even considering discrepancies among Latin American countries, the next actions should involve mechanisms to distribute and decentralize human resources with adequate quality at the subnational level in order to overcome barriers to eye care. The upcoming year can be an important year for the international public health since it marks the end of the first cycle of coordinated actions to eliminate hunger, reduce extreme poverty and foster better health and social development around the world. International eye care community should be able to mobilize and bring the control of blindness to the set of actions that are being prepared for the WHO second cycle of development of this millennium (2015-2035)(9). VISION 2020 actions on its home stretch can provide the initial backbone for this mobilization to make the world free of avoidable blindness in decades to come.

\section{REFERENCES}

1. Stevens GA, White RA, Flaxman SR, Price H, Jonas JB, Keeffe J, Leasher J, Naidoo K, Pesudovs K, Resnikofgf S, taylor H, Bourne RR; Vision Loss Expert Group. Global prevalence of vision impairment and blindness: magnitude and temporal trends, 1990-2010. Ophthalmology. 2013;120(12):2377-84.

2. Bourne RR, Stevens GA, White RA, Smith JL, Flaxman SR, Price H, Jonas JB, Keeffe J, Leasher J, Naidoo K, Pesudovs K, Resnikoff S, Taylor HR; Vision Loss Expert Group. Causes of vision loss worldwide, 1990-2010: a systematic analysis. Lancet Glob Health. 2013;1(6):e339-49. Comment in: Lancet Glob Health. 2013;1(6):e311-2; Lancet Glob Health. 2014;2(2):e76-7.

3. Ackland P. The accomplishments of the global initiative VISION 2020: The Right to Sight and the focus for the next 8 years of the campaign. Indian J Ophthalmol. 2012; 60(5):380-6.

4. World Health Organization. Universal eye health: a global action plan 2014-2019 [Internet]. Geneva:WHO; 2013. [cited 2014 Jun 21]. Available from: http://www.who.int/blindness/ AP2014_19_English.pdf?ua=1

5. Pan American Health Organization. Plan de acción para la prevención de la ceguera y de las deficiencias visuales [Internet]. Wahington: PAHO; 2014. [cited 2014 Oct 1]. Available at: https://vision2020la.files.wordpress.com/2014/07/plan-de-accic3b3n.pdf

6. Thylefors B, Négrel AD, Pararajasegaram R, Dadzie KY. Global data on blindness. Bul World Health Organ. 1995;73(1):115-21.

7. Furtado JM, Lansingh VC, Carter MJ, Milanese MF, Peña BN, Ghersi HA, et al. Causes of blindness and visual impairment in Latin America. Surv Ophthalmol. 2012;57(2):149-77.

8. Yaacov-Peña F, Jure D, Ocampos J, Samudio M, Furtado JM, Carter M, et al. Prevalence and causes of blindness in an urban area of Paraguay. Arq Bras Oftalmol. 2012;75(5): 341-3.

9. Jamison DT, Summers LH, Alleyne G, Arrow KJ, Berkley S, Binagwaho A, Bustreo F, Evans D, Feachem RG, Frenk J, Ghosh G, Goldie SJ, Guo Y, Gupta S, Horton R, Kruk ME, Mahmoud A, Mohohlo LK, Ncube M, Pablos-Mendez A, Reddy KS, Saxenian H, Soucat A, Ulltveit-Moe KH, Yamey G. Global health 2035: a world converging within a generation. Lancet. 2013;382(9908):1898-955. Erratum in: Lancet. 2014;383(9913):218. Comment in: Lancet. 2014;383(9921):949; Lancet. 2014;383(9921):949-50; Lancet 2014:383(9921):950-1; Lancet. 2013;382(9908):e38-9; Lancet. 2013:382(9908):e34-5: Lancet. 2013; 82(9908):e36-7; Lancet. 2013;382(9908):e33-4; Lancet. 2013;382(9908): 1859-61; Lancet. 2013;382(9908):1861-4

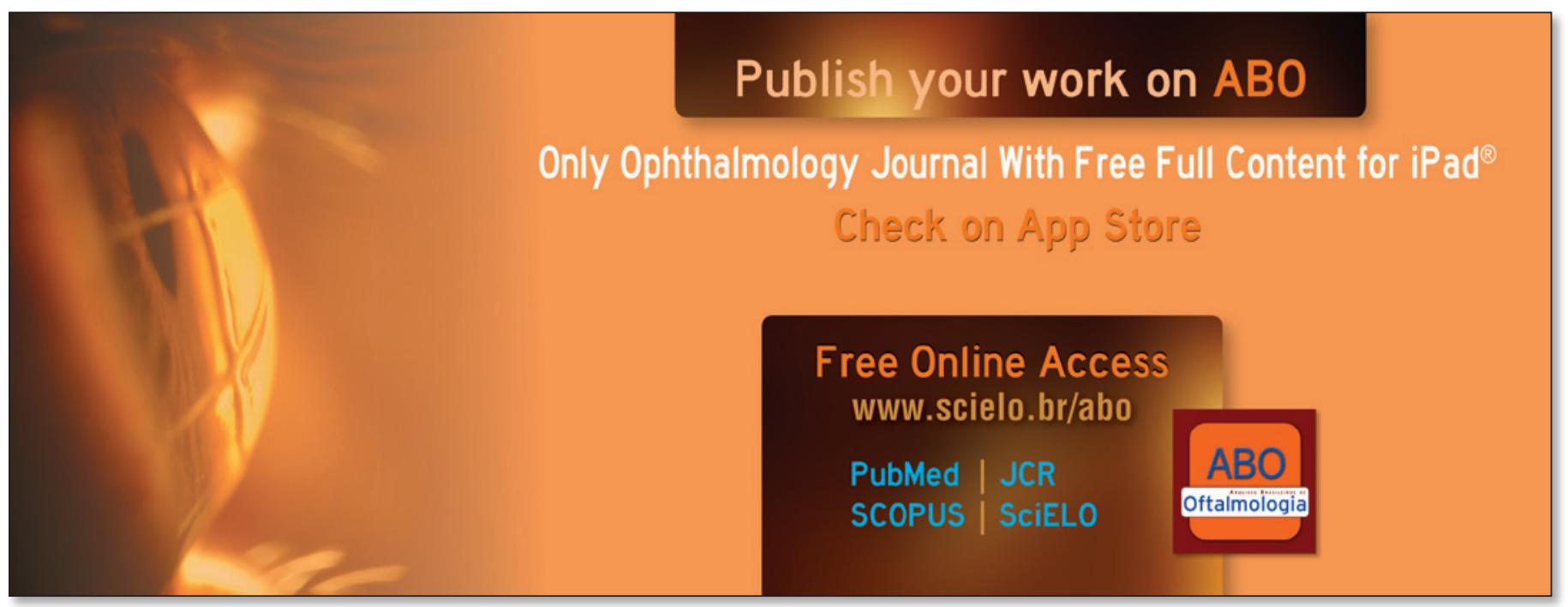

